\title{
Modifications of mechanical, thermal, and electrical characteristics of epoxy through dispersion of multi-walled carbon nanotubes in supercritical carbon dioxide
}

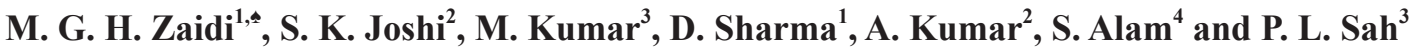 \\ ${ }^{1}$ Department of Chemistry, National Institute of Technology, Kurukshetra, 136119, India \\ ${ }^{2}$ Department of Physics, National Institute of Technology, Kurukshetra, 136119, India \\ ${ }^{3}$ Department of Mechanical Engineering, G.B. Pant University of Agriculture and Technology, Pantnagar, 263 145, India \\ ${ }^{4}$ Polymer Division, Defense Materials Stores Research Development and Establishment, G.T. Road, Kanpur, 208 013, India
}

\section{Article Info}

Received 12 July 2013

Accepted 20 September 2013

*Corresponding Author

E-mail: mgh_zaidi@yahoo.com Tel: +919411159853

\section{Open Access}

DOI: http://dx.doi.org/

10.5714/CL.2013.14.4.218

This is an Open Access article distributed under the terms of the Creative Commons Attribution Non-Commercial License (http://creativecommons.org/licenses/ by-nc/3.0/) which permits unrestricted non-commercial use, distribution, and reproduction in any medium, provided the original work is properly cited.

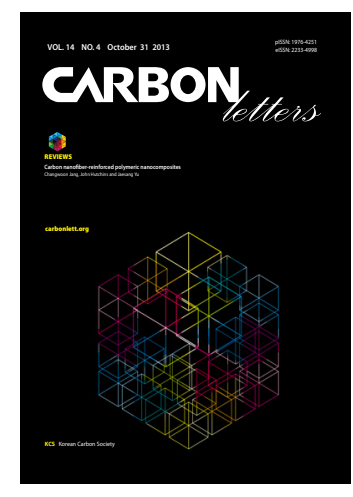

http://carbonlett.org

pISSN: $1976-4251$

elSSN: 2233-4998

Copyright $\odot$ Korean Carbon Society

\begin{abstract}
A supercritical carbon dioxide (SCC) process of dispersion of multi-walled carbon nanotubes (MWCNTs) into epoxy resin has been developed to achieve MWCNT/epoxy composites (CECs) with improved mechanical, thermal, and electrical properties. The synthesis of CECs has been executed at a MWCNT (phr) concentration ranging from 0.1 to 0.3 into epoxy resin $(0.1 \mathrm{~mol})$ at $1800 \mathrm{psi}, 90^{\circ} \mathrm{C}$, and $1500 \mathrm{rpm}$ over $1 \mathrm{~h}$ followed by curing of the MWCNT/epoxy formulations with triethylene tetramine (15 phr). The effect of SCC treatment on the qualitative dispersion of MWCNTs at various concentrations into the epoxy has been investigated through spectra analyses and microscopy. The developed SCC assisted process provides a good dispersion of MWCNTs into the epoxy up to a MWCNT concentration of 0.2. The effects of SCC assisted dispersion at various concentrations of MWCNTs on modification of mechanical, thermal, dynamic mechanical thermal, and tribological properties and the electrical conductivity of CECs have been investigated.
\end{abstract}

Key words: supercritical carbon dioxide, multi-walled carbon nanotube, epoxy, nanocomposites, mechanical and thermal properties

\section{Introduction}

The importance of supercritical fluids, particularly supercritical carbon dioxide (SCC), as a green friendly alternative to organic solvents for environmentally benign processing of carbon nanomaterials has recently been recognized [1-3].They have been adopted either to develop new technologies or to replace traditional technologies based on the use of organic solvents. The advantages of using SCC over conventional methods for processing of carbon nanomaterials are not only environmental but also chemical and economical. Due to its unique inexpensive, non-toxic, and non-flammable properties and excellent recyclability without energy expenditures, SCC has been used for processing of one dimensional carbon nanostructures [1], synthesis of carbon nanotubes (CNTs) [2,3], patterning of carbon nanomaterials [4], growth of CNTs [5] and carbon nanocages [6], purification of sing-walled CNTs (SWCNTs) [7,8], coating of inorganic nanoparticles [9] and polymers over carbon nanostructured surfaces [10], non-covalent functionalization of CNTs with molecular anchors [11], and preparation of endohedral derivatives of CNTs [12] and CNT/polymer composites [13-15].

Synthesis of epoxy based polymer nanocomposites incorporating CNTs is impeded by van der Waals interactions that limit the nanotube dispersion into the polymer matrix [16,17]. Remarkable improvements in the physical and barrier properties of these nanocomposites can be achieved by improving the dispersion of CNTs into the polymer matrix, which facilitates better wetting and in- 
creased surface contact area between the constituent phases [18-24]. In recent decades, efforts have been directed towards the development of physical-mechanical or chemical processes to enhance the dispersion of CNTs in an epoxy matrix [25-29]. Physical methods involve breaking up agglomerates through calendaring, grinding, ball milling, high speed shearing, high-pressure homogenization, ultrasonication, a combination thereof [30,31], or chronoamperometry [32]. With regard to chemical methods, the purification procedure involves the removal of metallic catalyst residues, which arise from the synthesis of CNTs and the creation of functional groups on their surface to improve the interfacial interactions between the polymers and CNTs $[16,31,32]$. CNTs are seriously damaged, especially when a probe sonicator is employed, suggesting the generation of defects on the CNT surface. In extreme cases, the graphene layers of CNTs are completely destroyed and the nanotubes are converted into amorphous carbon nanofibers. The localized damage to CNTs deteriorates both the electrical and mechanical properties of the multi-walled CNT (MWCNT)/epoxy composites (CECs) [19]. Mechanical dispersion, on the other hand, involves the use of expensive, toxic, and flammable organic solvents and lengthens the manufacturing process. The calendering approach has proved to be an effective method for achieving appropriate nanoreinforcement dispersion in epoxy resins without causing major damage to the nanoreinforcement compared to sonication and high shear mixing techniques, which present limited dispersion effectiveness and may cause damage to the nanoreinforcement when the processing time is lengthened to increase dispersion [31]. With respect to evaluating the dispersion of different types of nanoparticles, depending on the demanded scale, different microscopy methods such as transmission electron microscopy, scanning electron microscopy, and atomic force microscopy are amongst the most widely used techniques. In addition, dispersion of CNTs can be estimated indirectly by UVvis spectra [20], a disc centrifuge method [29], and light transmittance and electrical conductivity measurements [33].

To address the desperate need for effective dispersion of nanotubes into an epoxy matrix together with strong interfacial adhesion to achieve CECs with improved mechanical, thermal, and electrical properties, a SCC assisted process of dispersion of MWCNTs into epoxy has been developed. The influence of the concentration (phr) of MWCNTs, ranging from 0.1 to 0.3 , on their qualitative dispersion into epoxy under identical processing conditions of SCC has been investigated to achieve CECs with enhanced mechanical, thermal, and electrical properties.

\section{Materials and Methods}

Commercially available epoxy diglycidyl ether of bisphenol A (DGEBA) and the curing agent triethylene tetramine were purchased from M/S Huntsman India Limited. Epoxy equivalent of DGEBA (197 g/Eq) was deduced according to the pyridinium chloride method [16]. MWCNTs (diameter $20 \mathrm{~nm}, 99.5 \%$ ) were obtained from SES Research, Houston, USA.

\subsection{Synthesis of CECs through SCC assisted dispersion of MWCNTs}

Dispersion of MWCNTs into an epoxy resin assisted with SCC has been conducted in a stainless steel high pressure re- actor $\left(100 \mathrm{~cm}^{3}\right)$, manufactured by Pressure Products Industries USA, equipped with a PID temperature controller $\left( \pm 1^{\circ} \mathrm{C}\right)$. The reactor was charged with DGEBA $(0.1 \mathrm{~mol})$, the requisite concentration of MWCNTs (phr), and carbon dioxide (99.98\%). Contents were heated at pressure ranging from 1200 to $1800 \mathrm{psi}$, $90^{\circ} \mathrm{C}$, and $1500 \mathrm{rpm}$ for $1.0 \mathrm{~h}$ in SCC. The temperature of the cell was reduced to $40^{\circ} \mathrm{C}$ while maintaining mechanical agitation and subsequently $\mathrm{CO}_{2}$ was vented from the cell @ 50 psi/ min and into dichloromethane. This was followed by subsequent degassing of the contents at $10 \mathrm{mmHg}$. MWCNT/epoxy formulations were isolated from the reactor cell and investigated in terms of their dispersion through UV-vis spectra [20,33]. Supercritical conditions that may provide enhanced dispersion of MWCNTs into the epoxy on the basis of van Hove singularities have been identified and the respective MWCNT/epoxy formulations were degassed at $10 \mathrm{mmHg}$ and subsequently cured with triethylene tetramine ( $15 \mathrm{phr}$ ) to achieve CECs. All the samples were left at room temperature for $24 \mathrm{~h}$ and further post-cured for $3 \mathrm{~h}$ at $60^{\circ} \mathrm{C}$ for $30 \mathrm{~min}$.

\subsection{Characterizations}

\subsubsection{Dispersion of MWCNTs into epoxy}

Prior to curing, preliminary optimization of the dispersions of MWCNT in neat epoxy was achieved by monitoring the UVvis spectra of various supercritically processed MWCNT/epoxy resin formulations $[20,33]$. UV-vis spectra were recorded on a Genesis 10 Spectronic spectrophotometer in toluene at increments of $3 \mathrm{~nm}$. Dispersion of MWCNTs at the surface of CECs was investigated through atomic force microscopy (AFM). AFM images were recorded on a NTEGRA Prima microscope under tapping mode using ultra-sharp Si cantilevers having a force constant of $48 \mathrm{~N} / \mathrm{m}$ at room temperature. The qualitative extent of dispersion of MWCNTs in the CECs was investigated through scanning electron microscopy (SEM) using gold coated samples on a JEOL 6610 LV.

\subsubsection{DC electrical conductivity}

DC conductivity of the samples was recorded on a Keithley Nanovoltmeter model 2182 A coupled with a 6221 current source and an indigenous sample holder with a PID controlled oven provided by Scientific Instruments, Roorkee, India. Two parallel surfaces of each sample $1 \mathrm{~mm}$ apart were polished with silver paint and checked for good electrical conduction. Conductivity of samples was recorded through the four probe method at compliance of $2 \mathrm{~V} \mathrm{DC}$ at $35 \pm 1{ }^{\circ} \mathrm{C}$.

\subsubsection{Fourier transformed infra-red spectra}

Fourier transformed infra-red (FT-IR) spectra of the samples were recorded on a Perkin Elmer spectrophotometer in $\mathrm{KBr}$, with a resolution of $4 \mathrm{~cm}^{-1}$ from 4000 to $500 \mathrm{~cm}^{-1}$ in transmission mode.

\subsubsection{Mechanical characterizations}

A plint wear and friction Sr. No. TE 97/7050 fitted with a Muyford super lathe, dead weight tester, transducer with calibration of $0.892 \mathrm{mv} / \mathrm{v}$, microscope, and chart recorder was used in the present work. It consists of a modified lathe carrying a disc-shaped specimen on a mandrel with two pins pressed into 
contact with opposite surfaces of the disc by means of hydraulic cylinders. Hydraulic end loading was applied by means of a precision dead-weight pressure tester that can be loaded with dead weights to give any pressure up to 15 bar (b) in steps of $0.25 \mathrm{~b}$. A conical hole, having an included angle of $60^{\circ}$ and a maximum diameter of about $5 \mathrm{~mm}$, was drilled on the end face of each cylindrical pin. The wear loss was estimated by weighing the mass of the pin after every $60 \mathrm{~s}$ by a weighing machine. The rate of rotation of the disc was indicated by a tachometer in the control panel. In addition, elapsed time and cumulative number of revolutions were indicated on a digital counter equipped in the panel. The Rockwell hardness (R scale, RH) of the samples was evaluated over a hardness testing machine using a ball indenter with 1/16" diameter. Tensile strength data of samples with dimensions of $160 \times 10 \times 5$ were recorded at a cross head speed of $1.0 \mathrm{~mm} / \mathrm{min}$ on a KIPL-PC 2000 computer controlled electronic tesnometer. The load capacity of the machine was 20 $\mathrm{KN}$. This rather low loading rate was selected to consider the brittle character of the composites. The thickness of the samples was assigned at $3 \mathrm{~mm} \pm 0.5 \mathrm{~mm}$. About six to eight specimens were tested for each sample and the average value was obtained from data of these measured specimens. Compressive strength of samples with dimensions of $12.7 \times 12.7 \times 25.4 \mathrm{~mm}$ was measured on a Tinus Olson made universal testing machine (Capacity $35 \mathrm{KN}$ ) with a test speed of $5.0 \mathrm{~mm} / \mathrm{min}$. Impact strength of samples with dimensions of $64 \times 12.7 \times 3.2 \mathrm{~mm}$ and depth under the notch of $10.2 \mathrm{~mm}$ was recorded on a Izod Impact Tester (CEAST). The notch was prepared using a notch cutter with a micrometer screw gauge with $0.001 \mathrm{~mm}$ accuracy and a venire calliper (accuracy-0.001 mm). A dynamic mechanical thermal analysis (DMTA) was performed on TA Instrument 2980, operated in three point bending (flexural) mode, with sample dimensions of $60 \times 10 \times 4 \mathrm{~mm}$, a dual cantilever clamp, and an oscillation frequency of $1 \mathrm{~Hz}$. Data were collected from $20^{\circ} \mathrm{C}$ to $180^{\circ} \mathrm{C}$ at a scanning rate of $5^{\circ} \mathrm{C} / \mathrm{min}$ in air.

\subsubsection{Thermal characterizations}

Thermo-oxidative stability of the samples was investigated at a sample size $(\mathrm{mg})$ ranging from 8.085-11.020 through a simultaneous thermogravimetric-differential thermogravimetry-differential thermal analysis (TG-DTG-DTA) on a EXSTAR TG/ DTA 6300 instrument in static air at a heating rate of $10^{\circ} \mathrm{C} / \mathrm{min}$ up to $800^{\circ} \mathrm{C}$ using alumina powder as a reference. Differential scanning caloriemetry (DSC) of the samples was executed on a Universal V4.2E thermal analyzer at a heating rate of $10^{\circ} \mathrm{C} / \mathrm{min}$ in nitrogen.

\section{Results and Discussion}

Solubility behavior of oxirane functional molecules under tuned conditions of pressure, density, and temperature in SCC has been well documented but has not been reported in the context of dispersing carbon nanomaterials in SCC [34]. In the present investigation, the dispersion behavior of different concentrations (phr) of MWCNTs ranging from 0.1 to 0.3 into epoxy resin $(0.1 / \mathrm{dL}$ mole) has been investigated under the pressure of SCC ranging from 1200 to 1800 , at $90^{\circ} \mathrm{C}$, and $1500 \mathrm{rpm}$ over $1 \mathrm{~h}$. All the processes involved in dispersion of MWCNTs into epoxy

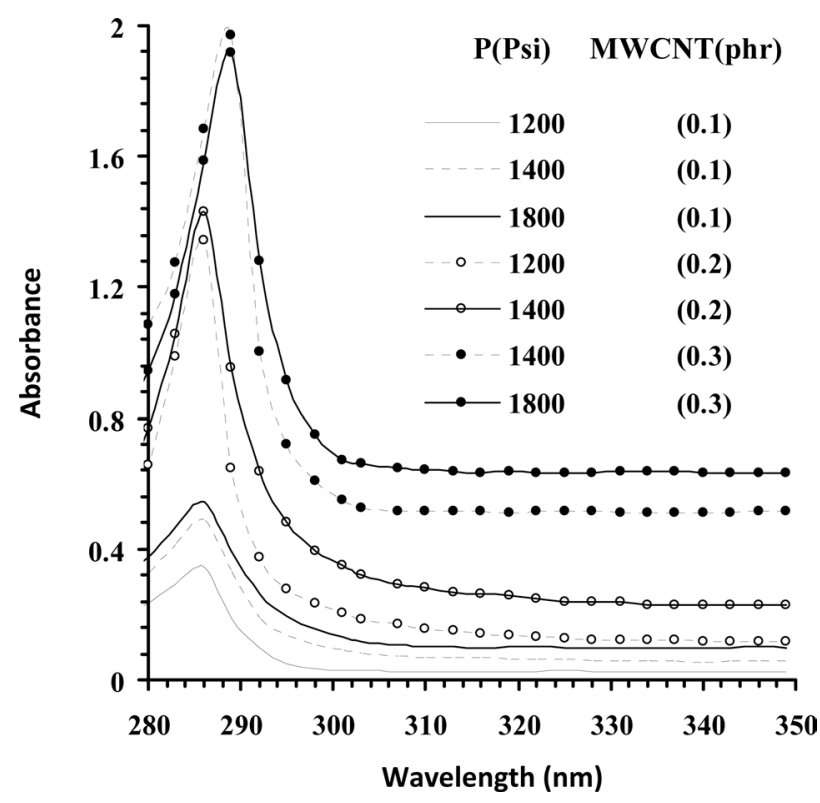

Fig. 1. Effect of pressure of supercritical carbon dioxide on the UV-vis spectral absorbance of multi-walled carbon nanotube (MWCNT)/epoxy dispersions processed at $90^{\circ} \mathrm{C}, 1 \mathrm{~h}, 1500 \mathrm{rpm}$.

have been optimized through UV-vis spectroscopy on the basis of van Hove singularities [20]. Fig. 1 illustrates the effect of pressure on the absorption maxima centered at around $286 \mathrm{~nm}$ of the formulations of MWCNT/epoxy resin prepared at various concentrations in SCC. If MWCNTs are dispersed in epoxy resin on a scale of nano-sized particles, the respective formulations should evince higher absorbance at the same concentration of MWCNTs due to absorption on the interfaces between the CNTs and the epoxy resin. With pressure of SCC, the intensity of absorption for each of the formulations was increased irrespective of the concentration of MWCNTs. Dispersion of MWCNTs at $0.1 \mathrm{phr}$ into epoxy $(0.1 \mathrm{~mole} / \mathrm{dL})$ at $1200 \mathrm{psi}$ showed a peak intensity of 0.346 , which has been optimized to 0.544 at 1800 psi. An increase in the concentration of MWCNTs to 0.2 resulted in an increase in the peak intensity to 1.345 at $1200 \mathrm{psi}$, optimized to 1.431 at 1400 psi. Further increase in the concentration of MWCNTs to $0.3 \mathrm{phr}$ increased the peak intensity of 1.919 at $1400 \mathrm{psi}$, optimized to 1.973 at $1800 \mathrm{psi}$. Such optimization of the peak intensity may be attributed to enhanced dispersion of MWCNTs into the epoxy resin at 1800 psi under applied conditions of temperature, stirring rate, and time in SCC. The epoxy formulations prepared at 1800 psi were therefore cured with TETA at 15 phr with the aim of obtaining CECs with comparable physical properties.

The effect of SCC assisted dispersion of various concentrations of MWCNTs into epoxy on the microstructure of respective CECs has been investigated through compositional mapping with AFM (Fig. 2). AFM images at a scan size of $10 \mu \mathrm{m}$ revealed a biphasic composition of CECs with bright and dark areas. The images show large smooth zones with a bright appearance corresponding to the MWCNTs, and small entities with a grainy aspect identifiable as ordered domains of epoxy resin, forming a dark phase. The inherent properties of the phases are related to their relative phase contrast. Brighter areas of 

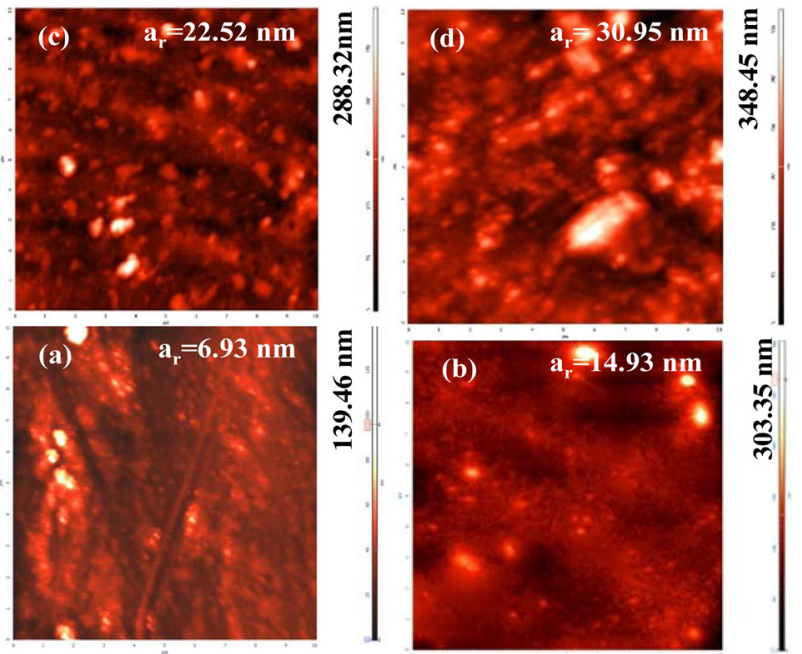

Fig. 2. Atomic force microscopy images $(X Y=10 \mu \mathrm{m})$ of cured epoxy (a) and multi-walled carbon nanotube (MWCNT)/epoxy composites synthesized through supercritical carbon dioxide assisted dispersion at MWCNT concentration (phr) of 0.1 (b), 0.2 (c) and 0.3 (d).

AFM images may be attributed to the greater force experienced by the cantilever tip during contact with MWCNTs, whereas dark areas of the image correspond to amorphous phases due to the epoxy matrix. Cured epoxy (Fig. 2a) shows relatively more dark areas due to its brittle nature, and these areas become been brighter with higher concentrations of MWCNTs (Figs. 2b and d). CECs synthesized up to a MWCNT concentration of 0.2 do not show significant aggregates of MWCNTs, indicating that the interaction between MWCNTs and the epoxy resin helps reduce the possibility of large agglomerations. CECs synthesized at a MWCNT concentration of 0.3 reveal the presence of organized bundles in the epoxy matrix (Fig. 2d).

The extent of relative changes of the phase morphology of CECs has further been explored through examination of their average roughness $\left(\mathrm{a}_{\mathrm{r}}, \mathrm{nm}\right)$. Cured epoxy shows average roughness $\left(\mathrm{a}_{\mathrm{r}}, \mathrm{nm}\right)$ of 6.93 at an indenter height $(\mathrm{nm})$ of 139.46 (Fig. 2a). With increasing concentration of MWCNTs, a gradual increase in the $\mathrm{a}_{\mathrm{r}}$ of the respective CECs has been observed. CECs synthesized at a MWCNT concentration of 0.1 shows an $\mathrm{a}_{\mathrm{r}}$ of 14.93 at an indenter height of 302.35 (Fig. 2b). An increase in $a_{r}$ to 22.52 was observed at an indenter height of 288.32 for CECs synthesized at a MWCNT concentration of 0.2 (Fig. 2c). CECs synthesized at a MWCNT concentration of 0.3 showed an increase in $\mathrm{a}_{\mathrm{r}}$ to 30.95 at an indenter height of $348.45[29,35,36]$.

A SEM analysis of cured nanocomposites reveals the increasing tendency of reaggregation of MWCNTs in the epoxy with increasing nanotube concentration. Fig. 3a shows a SEM of CECs at $1 \mathrm{KX}, 10 \mu \mathrm{m}$, synthesized by dispersing MWCNTs at $0.1 \mathrm{phr}$ in SCC. The micrograph reveals a good dispersion of MWCNTs into the epoxy matrix, likely due to destruction of their entanglement networks. However, this has been associated with some agglomeration, which distinctly appeared at $5 \mathrm{KX}, 2 \mu \mathrm{m}$ (Fig. 3b). In order to gain insight into the extent of dispersion of MWCNTs according to their concentration in SCC, the study of microstructure of CECs was further conducted at $5 \mathrm{KX}, 2 \mu \mathrm{m}$. Upon increasing the concentration of MWCNTs into epoxy to 0.2 while retaining the identical supercritical processing condi-

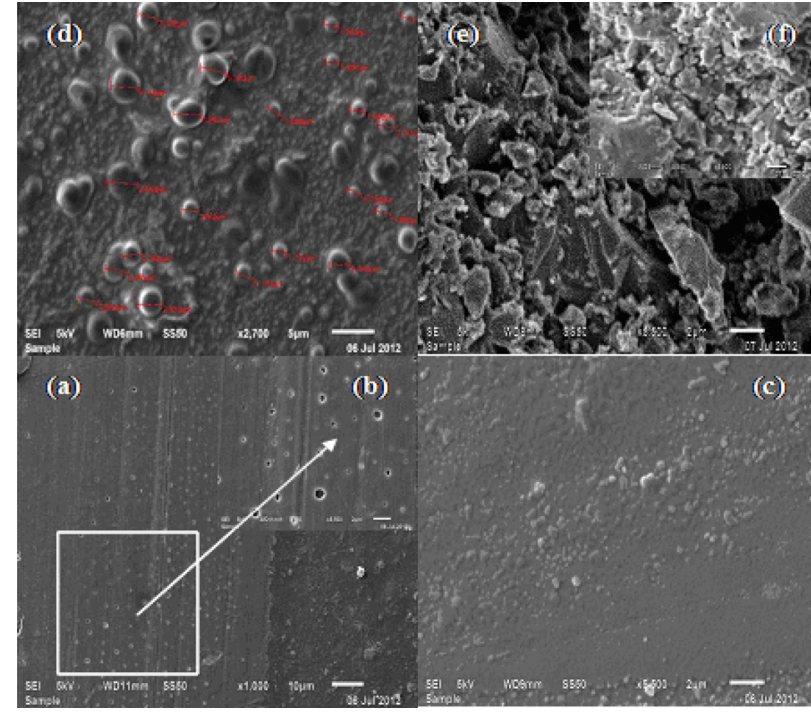

Fig. 3. Scanning electron microscopy images of multi-walled carbon nanotube (MWCNT)/epoxy composites (CECs) synthesized through supercritical carbon dioxide assisted dispersion at MWCNT concentration of $0.1 \mathrm{phr}$ at $1.0 \mathrm{KX}, 10 \mu \mathrm{m}$ (a), $0.1 \mathrm{phr}$ (b), $0.2 \mathrm{phr}$ (c), $0.3 \mathrm{phr}$ (d), fractured surface of CECs at $0.1 \mathrm{phr}(\mathrm{e})$ and $0.3 \mathrm{phr}(\mathrm{f})$ at $5.5 \mathrm{KX}, 2 \mu \mathrm{m}$.

tions, a slight increase in the tendency of agglomeration of MWCNTs in the epoxy matrix was observed due to their entanglement in the matrix (Fig. 3c). At a MWCNT concentration of 0.3, networks of clusters connected by individual MWCNTs with size $(\mu \mathrm{m})$ ranging from 1.54 to 3.65 have been formed (Fig. 3d) due to their high degree of entanglement in the epoxy matrix, which likely is responsible for their characteristic reagglomeration in the epoxy matrix [17].

Figs. $3 \mathrm{e}$ and $\mathrm{f}$ show different zones of the fractured surface of CECs synthesized at MWCNT concentrations of 0.1 and 0.3 . SEM reveals the presence of stress concentration in the matrix of fractured epoxy due to agglomeration of MWCNTs. With increasing concentration of MWCNTs, modification of the roughness of the fractured surface was observed mainly in the areas of the CECs where the crack propagation initiated, which is common in brittle epoxy resin fractures $[31,35,36]$. The spectral, microstructure, and electrical conductivity data reveal the capability of SCC to provide well dispersed MWCNT/epoxy formulations up to a filler concentration of 0.2 at applied supercritical processing conditions within $1 \mathrm{~h}$ without sonication [18,29,31].

SCC assisted dispersion of MWCNTs into epoxy has been further substantiated by the increase in their DC electrical conductivity $\left(\sigma_{\mathrm{DC}}, \mathrm{S} / \mathrm{cm}\right)$ with the concentration of MWCNTs. With increasing concentration of MWCNTs up to 0.2 , the $\sigma_{\mathrm{DC}}$ of CECs was increased by five orders of magnitude. The $\sigma_{\mathrm{DC}}$ of CECs with the well dispersed MWCNTs is two orders of magnitude higher than that of the CECs with poorly dispersed MWCNTs. For this reason it is easier for the well dispersed MWCNTs to form conductive paths due to their relatively homogeneous dispersion of nanoparticles compared to the case of aggregated MWCNTs [23]. It was confirmed that the percolation threshold for CECs was close to a MWCNT concentration of $0.2[32,35,36]$. The spectral, microstructure, and $\sigma_{\mathrm{DC}}$ data reveal the capability of SCC to provide well dispersed MWCNT/epoxy formulations up 


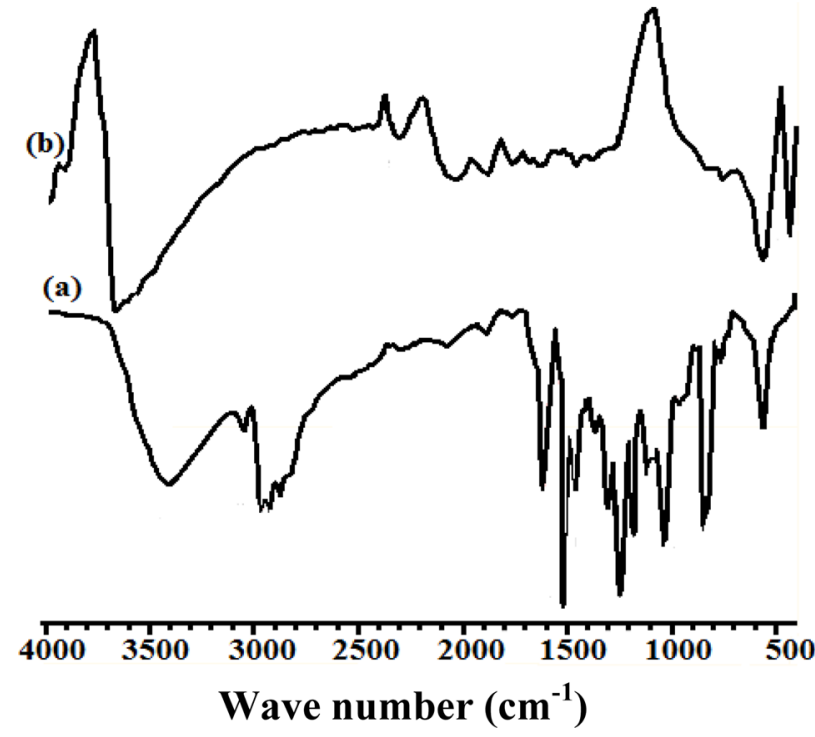

Fig. 4. Fourier transformed infra-red spectra of cured epoxy (a) and a multi-walled carbon nanotube (MWCNT)/epoxy composites synthesized at MWCNT concentration of $0.3 \mathrm{phr}$ in supercritical carbon dioxide.

to a filler concentration of 0.2 at applied supercritical processing conditions within $1 \mathrm{~h}$ without procedures of sonication or other related physical methods $[18,28,30]$.

The assignments of group frequencies at respective wave numbers $\left(\mathrm{cm}^{-1}\right)$ based on FT-IR spectra reveal the formation of CECs (Fig. 4). Cured epoxy shows wave numbers corresponding to characteristic group frequencies at $3670.25(v \mathrm{OH})$, $1756.23(v \mathrm{COOH}), 1673.27(\delta \mathrm{NH}), 1457.09(\delta \mathrm{CH})$, and 749.88 (oxirane ring). CECs synthesized at a MWCNT concentration of 0.3 shows characteristic absorptions at $3407.05(v \mathrm{OH}), 3039.73$ (Aromatic, v CH), 2962.47-2925.31 ( $\left.v_{\mathrm{as}}, \mathrm{CH}\right), 2868.10\left(v_{\mathrm{sy}}\right.$, $\mathrm{CH}), 1756.64(\mathrm{vCOOH}), 1608.32(\delta \mathrm{NH}), 1509.00(\delta \mathrm{NH}$, out of plane), 1460.33-1360.27 $(\delta \mathrm{CH}), 1297.58-1245.22\left(v_{\mathrm{as}}, \mathrm{CN}\right)$, $1180.78-1033.86\left(v_{\mathrm{sy}}, \mathrm{CN}\right), 828.98\left(\mathrm{CH}_{2}\right.$, twisting/wagging), and 763.68-730.99, corresponding to contraction of the epoxide ring.

\subsection{Mechanical properties}

Fig. 5 represents the effect of MWCNT concentration on control over wear loss $(\mathrm{mg} / \mathrm{min})$ of CECs at selected hydraulic end loads (bar) of 2.0 and 4.0 at a constant disc speed of 320 rpm. With increasing concentration of MWCNTs remarkable control over $\mathrm{W}_{\mathrm{L}}$ of the CECs was observed, and subsequently increased with hydraulic end load (Fig. 5a) and time (Fig. 5b). At $2 \mathrm{~b}$, cured epoxy shows a $\mathrm{W}_{\mathrm{L}}$ of 3.7 within $2.0 \mathrm{~min}$. With increasing concentration of MWCNTs, respective CECs show $\mathrm{W}_{\mathrm{L}}$ values ranging from 2.8 to 2.0 within 2.1 to $2.5 \mathrm{~min}$ at $2 \mathrm{~b}$. An increase in the hydraulic end load from $2.0 \mathrm{~b}$ to $4.0 \mathrm{~b}$ induced the observed increase in wear behavior of the cured epoxy and respective CECs. At $4 \mathrm{~b}$ the cured epoxy shows a $\mathrm{W}_{\mathrm{L}}$ of 4.0 within $2.3 \mathrm{~min}$, which was gradually controlled to 2.25 within $2.9 \mathrm{~min}$, corresponding to CECs synthesized at a MWCNT concentration of 0.3 .

In order to gain further insight into the remarkable control over the wear behavior of the CECs, their RH and impact

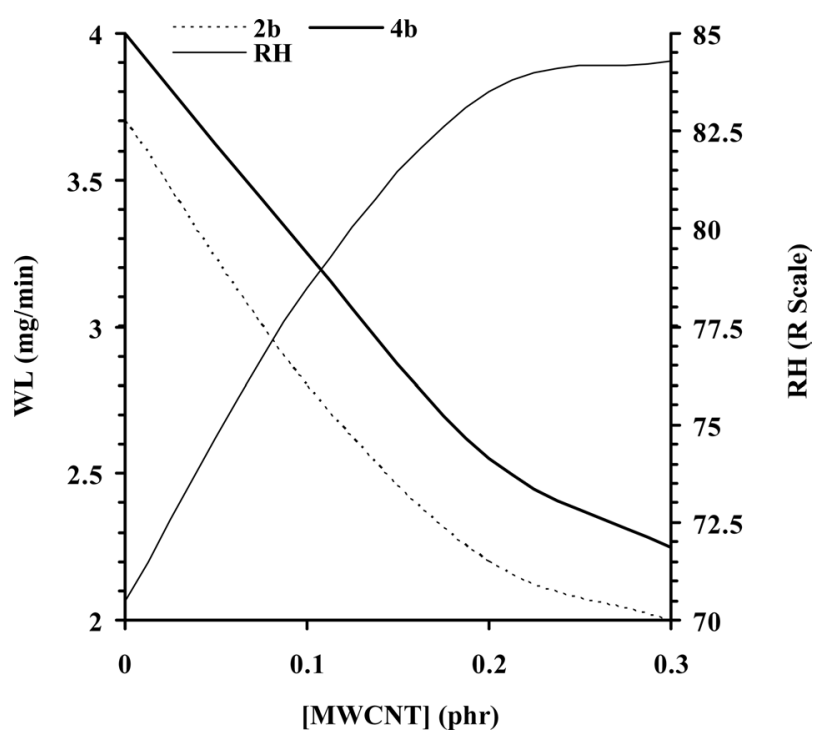

Fig. 5(a). Effect of multi-walled carbon nanotube (MWCNT) concentration (phr) on wear loss at $320 \mathrm{rpm}$ and Rockwell hardness of MWCNT/ epoxy composites (CECs).

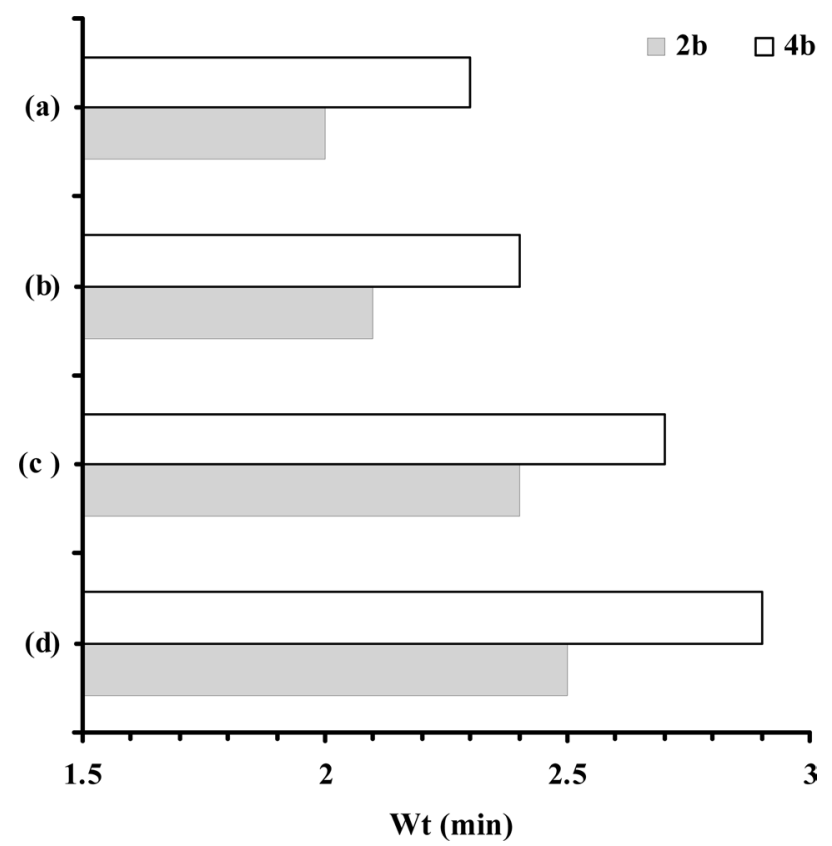

Fig. 5(b). Effect of hydraulic end load on wear time of CECs at 320 rpm.

strength $\left(\mathrm{kJ} / \mathrm{m}^{2}\right)$ were investigated. With $\mathrm{W}_{\mathrm{L}}$, a simultaneous increase in hardness and impact strength of CECs was observed, and this was further intensified with the concentration of MWCNTs. Cured epoxy shows a RH of 70.5. With increasing concentration of MWCNTs, a gradual increase in the RH of CECs was observed, ranging from 78.5 to 84.3 (Fig. 5a). Accordingly, the cured epoxy shows an impact strength of 17.16 , whereas with increasing concentration of MWCNTs, the impact strength of respective CECs increased from 21.48 to 31.01 .

Cured epoxy shows tensile strength and Young modulus 

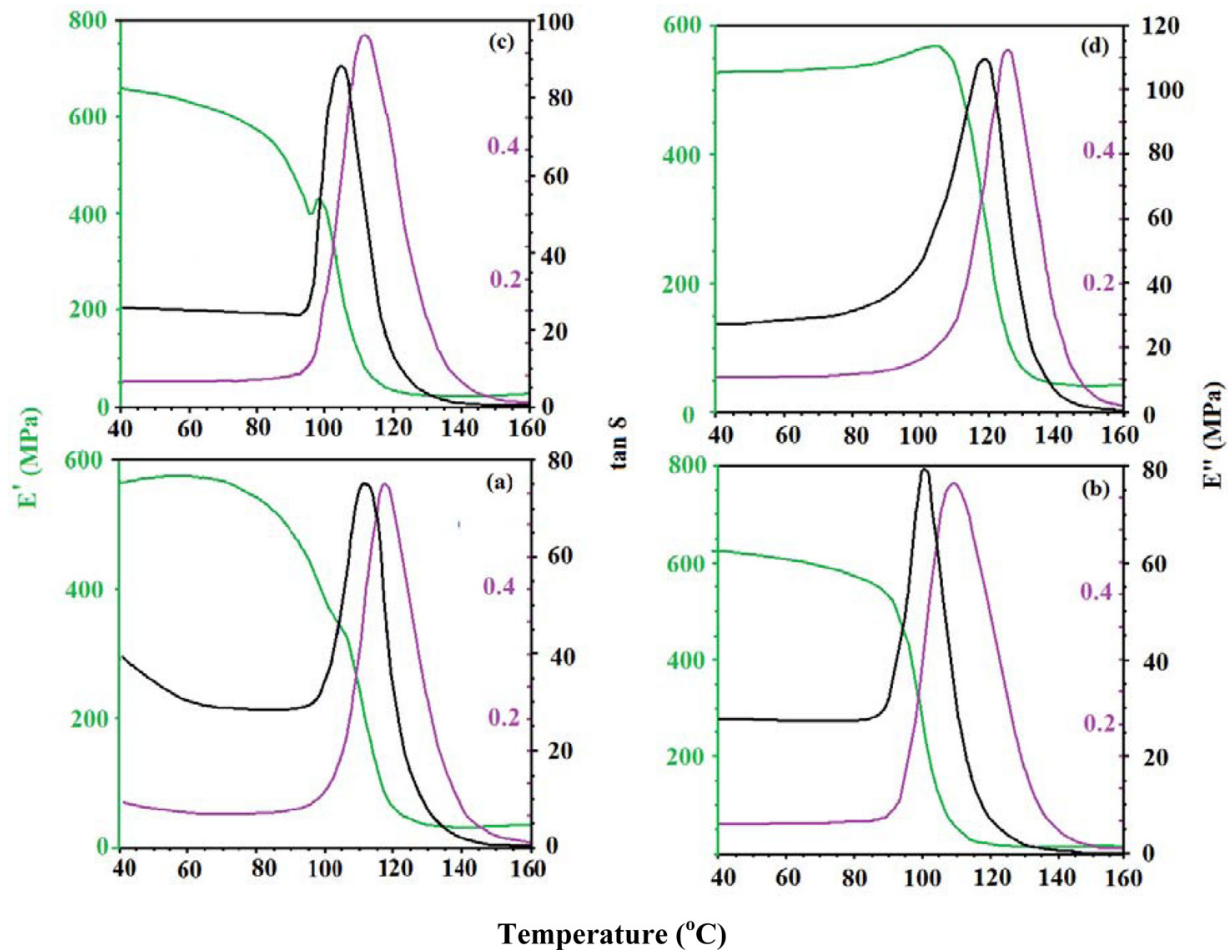

Fig. 6. Dynamic mechanical analysis scans of cured epoxy (a) and multi-walled carbon nanotube (MWCNT)/epoxy composites synthesized at MWCNT concentration (phr) of 0.1 (b), 0.2 (c) and 0.3 (d) in supercritical carbon dioxide.

(MPa) of 30.36 and 384.89 , respectively. At a low concentration of MWCNTs, a marginal increase in the tensile strength of CECs has been observed. With increasing concentration of MWCNTs, a gradual increase in the tensile strength of respective CECs, ranging from 36.44 to 49.36 , was observed. This has been accompanied by a simultaneous reduction in the Young moduli of respective CECs ranging from 389.18 to 369.95 . The loss in the Young moduli has further been supported with the compressive strength $(\mathrm{MPa})$ data. With increasing concentration of MWCNTs, a gradual loss in the compressive strength of epoxy has been observed, ranging from 131.80 to 110.70 . Such modifications in the wear performance, hardness, an impact and tensile strength with the concentration of MWCNTs may be assigned to interfacial bonding and enhanced dispersion of MWCNTs in SCC, their high specific mechanical properties, specific surface area, and good interfacial adhesion between CNTs and the matrix, which plays a role in enhancing the framework. This enhanced dispersion of MWCNTs restricts the mobility of polymer chains under loading and improved the modulus and strength at small loadings (Table 1).

Fig. 6 shows the effects of concentration of MWCNTs on the dynamic mechanical properties of CECs. The respective values of the elastic part of the complex modulus (storage), loss moduli $(\mathrm{MPa})$, and loss factor $(\tan \delta$ ) have been summarized (Table 1). The moduli of the CECs were higher over cured epoxy, due to the high stiffness of the MWCNTs. With increasing concentration of MWCNTs, a regular increase in both moduli of the CECs was observed. This increase in the loss modulus of the resin with the addition of MWNTs may be ascribed to the dispersion of MWCNTs, which led to a significant increase of the moduli both in a glassy and in a rubbery state. This increase in the elastic properties of CECs at elevated temperature may be attributed to interactions between the MWCNTs and the epoxy due to enormous surface area. This interfacial interaction reduces the mobility of the epoxy matrix around the nanotubes and leads to an observed increase in thermal stability.

$\mathrm{Tg}$ measurements are highly important as they determine the critical service temperature of materials for engineering applications. If the slope of the storage modulus values in the glass transition zone is used to estimate the $\mathrm{Tg}$ of the neat and the CECs, then it can be stated that, similar to the case of the storage modulus, the addition of MWCNTs led to a general increase of the $\mathrm{Tg}$ up to $110^{\circ} \mathrm{C}$, corresponding to CECs synthesized with a MWCNT concentration of 0.3 . The restricted mobility of the polymer chains around the nanotubes and the interfacial bonds between them also explain the increase in $\mathrm{Tg}$. This gain in thermostability can again be interpreted as a reduction of the mobility of the epoxy matrix around the nanotubes by the interfacial interactions. While the increase of the storage modulus at the glassy state with the addition of MWCNTs is a common observation due to the reinforcing effect of MWCNTs and restricted mobility of epoxy chains, CECs synthesized at a MWCNT concentration of 0.2 do not display rubbery modulus enhancements due to the drop in the Tg. With increasing concentration of MWCNTs, a regular increase in the loss modulus of CECs has been observed.

The loss modulus of CECs indicates the energy used to deform the material, which is dissipated into heat and can be used as a measurement of the viscous component or unrecoverable oscillation energy dissipated per cycle. The increase in the loss 
Table 1. Physical characteristics of CECs synthesized through SCC assisted dispersion of MWCNT into epoxy

\begin{tabular}{|c|c|c|c|c|}
\hline & \multicolumn{4}{|c|}{ CECs } \\
\hline & (a) & (b) & (c) & (d) \\
\hline $\operatorname{MWCNT}(\mathrm{phr})^{\mathrm{a}}$ & 0.00 & 0.10 & 0.20 & 0.30 \\
\hline \multicolumn{5}{|l|}{ Mechanical properties } \\
\hline Tensile strength (MPa) ${ }^{\mathrm{a}}$ & 30.36 & 36.44 & 47.73 & 49.36 \\
\hline Young's modulus (MPa) & 384.89 & 389.18 & 375.32 & 369.95 \\
\hline Impact strength $\left(\mathrm{kJ} / \mathrm{m}^{2}\right)^{\mathrm{b}}$ & 17.16 & 21.48 & 29.98 & 31.01 \\
\hline Compressive strength $(\mathrm{MPa})^{\mathrm{c}}$ & 131.80 & 126.90 & 117.30 & 110.70 \\
\hline \multicolumn{5}{|l|}{ TG onset } \\
\hline Moisture (\% w/w?) & 1.46 & 1.17 & 1.28 & 1.49 \\
\hline $\operatorname{Wr}\left({ }^{\circ} \mathrm{C}\right)^{d}$ & $96.6(250)$ & $96.4(250)$ & $96(250)$ & $95.7(250)$ \\
\hline$-\Delta \mathrm{H}_{\mathrm{D}}\left[\mathrm{J} / \mathrm{mg}\left({ }^{\circ} \mathrm{C}\right)\right]^{\mathrm{e}}$ & $0.42(284)$ & $0.56(287)$ & $0.63(287)$ & $0.67(283)$ \\
\hline $\mathrm{R}_{1}\left[\mathrm{mg} / \min \left({ }^{\circ} \mathrm{C}\right)\right]^{\mathrm{f}}$ & $0.45(281)$ & $0.46(287)$ & $0.50(265)$ & $0.52(282)$ \\
\hline $\mathrm{R}_{2}\left[\mathrm{mg} / \min \left({ }^{\circ} \mathrm{C}\right)\right]^{\mathrm{f}}$ & $0.49(330)$ & $0.41(331)$ & $0.39(326)$ & --- \\
\hline \multicolumn{5}{|l|}{ TG endset } \\
\hline $\mathrm{Wr}\left({ }^{\circ} \mathrm{C}\right)^{\mathrm{d}}$ & $0.7(550)$ & $0.8(550)$ & $0.4(550)$ & $2.7(550)$ \\
\hline$-\Delta \mathrm{H}_{\mathrm{D}}\left[\mathrm{J} / \mathrm{mg} \times 10^{-3}\left({ }^{\circ} \mathrm{C}\right)\right]^{\mathrm{e}}$ & $1.09(486)$ & $1.45(505)$ & $1.40(504)$ & $1.80(520)$ \\
\hline $\mathrm{R}_{3}\left[\mathrm{mg} / \min \left({ }^{\circ} \mathrm{C}\right)\right]^{\mathrm{f}}$ & $0.70(486)$ & $0.63(504)$ & $0.65(501)$ & $0.80(515)$ \\
\hline \multicolumn{5}{|l|}{ DSC data } \\
\hline$\Delta \mathrm{H}_{\text {cure }}\left[\mathrm{J} / \mathrm{g}\left({ }^{\circ} \mathrm{C}\right)\right]^{\mathrm{g}}$ & --- & $2.95(62.07)$ & $19.41(71.47)$ & $11.01(66.76)$ \\
\hline $\operatorname{Tg}\left({ }^{\circ} \mathrm{C}\right)^{\mathrm{h}}$ & 105.19 & 95.91 & 106.05 & 107.76 \\
\hline \multicolumn{5}{|l|}{ DMTA data } \\
\hline $\mathrm{E}^{\prime}(\mathrm{MPa})\left[\mathrm{T}_{\mathrm{g}},{ }^{\circ} \mathrm{C}\right]^{\mathrm{i}}$ & $508.60(87.04)$ & $537.30(89.46)$ & $599.70(73.53)$ & $566.70(110.00)$ \\
\hline $\mathrm{E}^{\prime \prime}(\mathrm{MPa})\left[\mathrm{T}_{\mathrm{g}},{ }^{\circ} \mathrm{C}\right]^{\mathrm{j}}$ & $75.51(111.66)$ & $79.64(100.65)$ & $88.32(104.68)$ & $110.00(118.72)$ \\
\hline $\operatorname{Tan} \delta\left(\mathrm{T}_{\mathrm{g}}{ }^{\circ} \mathrm{C}\right)$ & $0.56(117.31)$ & $0.57(108.82)$ & $0.57(111.55)$ & $0.56(125.47)$ \\
\hline$\sigma_{\mathrm{DC}}(\mathrm{S} / \mathbf{c m})^{\mathrm{k}}$ & $7.45 \times 10^{-8}$ & $4.63 \times 10^{-3}$ & $8.85 \times 10^{-3}$ & $3.55 \times 10^{-5}$ \\
\hline
\end{tabular}

CECs: multi-walled carbon nanotube/epoxy composites, SCC: supercritical carbon dioxide, MWCNT: multi-walled carbon nanotube, DSC: differential scanning caloriemetry, DMTA: dynamic mechanical thermal analysis.

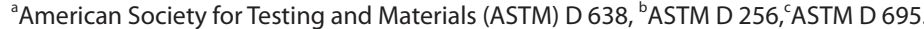

'Weight residue $(\%, w / w)$ from thermogravimetric (TG, temperature of degradation).

${ }^{\mathrm{e}} \mathrm{Heat}$ of degradation from differential thermal analysis (peak temperature).

${ }^{\text {f }}$ Rate of degradation from differential thermogravimetry (peak temperature)

${ }^{9}$ Curing enthalpy, ${ }^{\text {h}} \mathrm{T}_{\mathrm{g}}$, ${ }^{\mathrm{i}}$ storage modulus (MPa), ${ }^{\mathrm{j}}$ loss modulus (MPa).

${ }^{k}$ DC electrical conductivity.

modulus with increasing concentration of MWCNTs can be interpreted by enhanced susceptibility dispersion of MWCNTs into the epoxy, leading to less energy dissipation in the system under visco-elastic deformation. The well dispersed MWCNTs in the CECs must dissipate energy due to resistance against viscoelastic deformation of the surrounding matrix.

Loss factor $(\tan \delta)$ curves for the neat resin and the CECs can be used to evaluate their damping behaviors. An increase in the height of the tan $\delta$ curves of CECs synthesized at a MWCNT concentration $0.1 \mathrm{phr}$ was observed without an appreciable change in the width, suggesting that with the addition of $0.1 \mathrm{phr}$ MWCNTs there was a corresponding change in the energy absorption capability of the resin. However, with an increase in the concentration of MWCNT to $0.2 \mathrm{phr}$, a marginal increase in the loss factor was observed. This may be attributed to slight modification of the stiffening effect of epoxy due to the dispersion of MWCNTs. However, this is not the only mechanism that influences the way energy is dissipated in the modified systems. Note again that $\mathrm{Tg}$ is associated with the temperature where the $\tan \delta$ peak is observed, in the present study, a clear increase of 


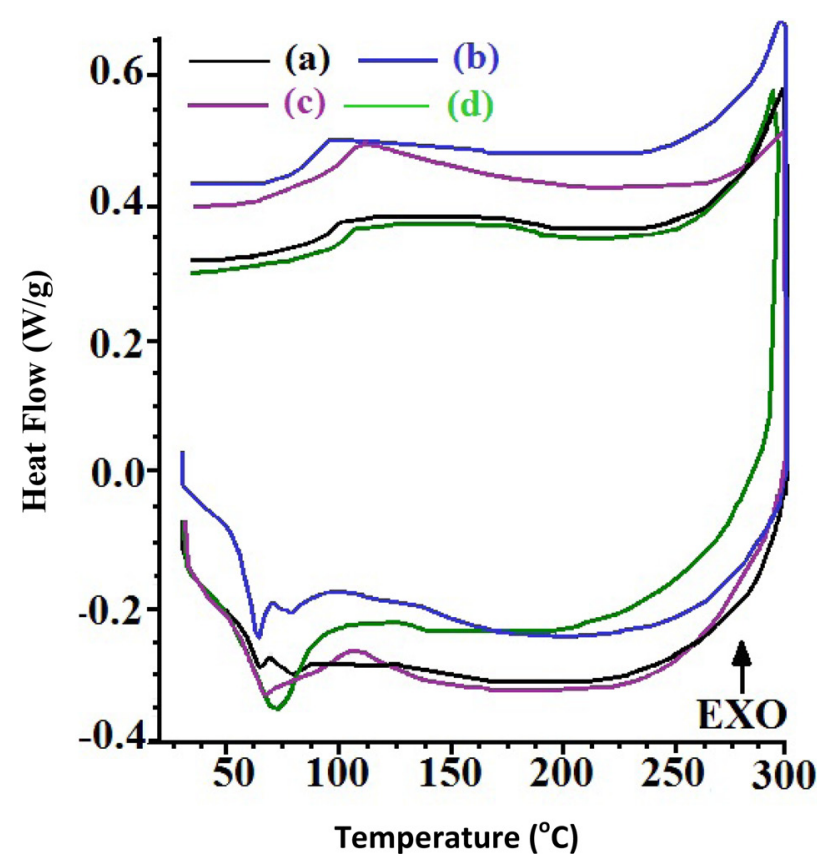

Fig. 7. Differential scanning caloriemetry scans of cured epoxy (a) and multi-walled carbon nanotube (MWCNT)/epoxy composites synthesized at MWCNT concentration (phr) of 0.1 (b), 0.2 (c) and 0.3 (d) in supercritical carbon dioxide.

the Tg value has been observed with increasing concentration of MWCNTs. This indeed indicates that the MWCNTs, at the investigated concentrations, have a remarkable effect on the relaxation phenomena, leading to the glass transition of the system. This significant increase of the moduli and Tg of CECs may be attributed to improved dispersion and interfacial bonding between the CNTs and the epoxy matrix. The Tg data evaluated through DMA at the loss modulus were further found to be in proximity with DSC (Table 1). Cured epoxy showed a $\mathrm{Tg}\left({ }^{\circ} \mathrm{C}\right)$ of 105.19. CECs synthesized at a MWCNT concentration of 0.1 have shown a reduction in $\mathrm{Tg}$ to 95.91. A further increase in the concentration of MWCNTs contributed to a remarkable increase in the $\mathrm{Tg}$ of CECs up to 107.76. This increase is ascribed to increased density and decreased mobility of the polymer chains. [37].

\subsection{Thermal properties}

The study of the curing behavior of MWCNT-filled epoxies is of immense importance for designing respective nanocomposites and optimization of their fabrication. The curing behavior of epoxy and respective MWCNT/epoxy formulations synthesized in SCC has been investigated through DSC (Fig. 7). Cured epoxy shows a very weak peak corresponding to curing enthalpy, indicating their complete polymerization. The curing enthalpy $\left(\Delta \mathrm{H}_{\text {cure }}, \mathrm{J} / \mathrm{g}\right)$ of CECs has been increased to 19.41 up to a concentration of MWCNTs of 0.2. CECs synthesized at a MWCNT concentration of 0.1 show an exothermic peak $\left({ }^{\circ} \mathrm{C}\right)$ centered at 62.07 with corresponding curing enthalpy $\left(\Delta \mathrm{H}_{\text {cure }}, \mathrm{J} / \mathrm{g}\right)$ of 2.95 . Further increase in the concentration of MWCNTs to 0.2 yielded an exothermic peak centered at 71.47 with a $\Delta \mathrm{H}_{\text {cure }}$ of 19.41 . Further increase in the concentration of MWCNTs shifted the exothermic peak to 66.76 with a corresponding reduction in $\Delta \mathrm{H}_{\text {cure }}$ to 11.01 . This increase in the $\Delta \mathrm{H}_{\text {cure }}$ value may be attributed to acceleration of the curing process up to a MWCNT concentration of 0.2 (Table 1).

Cured epoxy and respective CECs have shown two-step de-
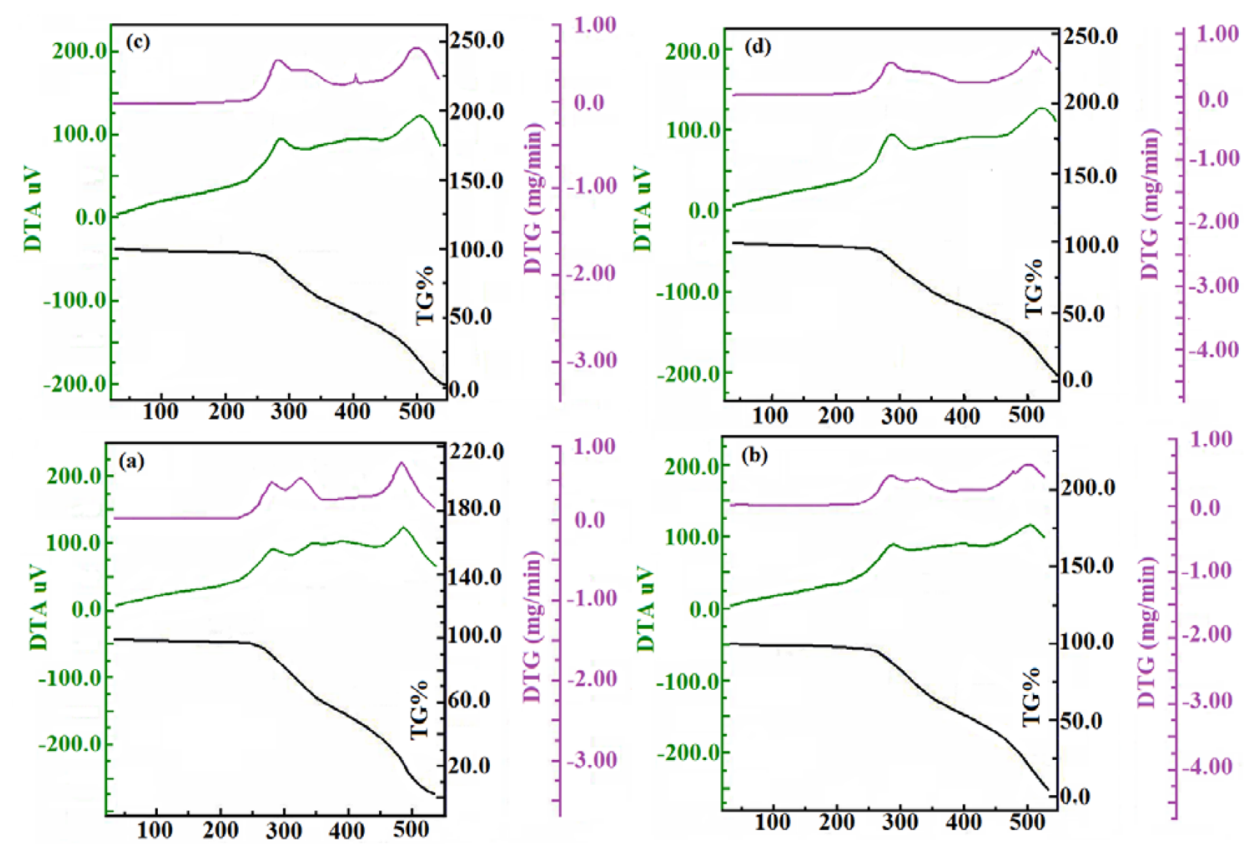

Temperature $\left({ }^{\circ} \mathrm{C}\right)$

Fig. 8. Simultaneous thermogravimetric-differential thermogravimetry-differential thermal analysis (TG-DTG-DTA) scans of cured epoxy (a) and multi-walled carbon nanotube (MWCNT)/epoxy composites synthesized at MWCNT concentration (phr) of 0.1 (b), 0.2 (c) and 0.3 (d) in supercritical carbon dioxide. 
composition with common temperatures corresponding to TG onset $\left(250^{\circ} \mathrm{C}\right)$ and endset $\left(550^{\circ} \mathrm{C}\right)$. Cured epoxy and the respective CECs retained their respective weights $\left(\mathrm{W}_{\mathrm{r}}, \% \mathrm{w} / \mathrm{w}\right)$ of around 96 at the common TG onset, indicating remarkable heat resistance up to $250^{\circ} \mathrm{C}$. With increasing MWCNT concentration, in general, all CECs decomposed at higher rates $(\mathrm{mg} / \mathrm{min})$ at the first step of decomposition ranging from 265 to $287^{\circ} \mathrm{C} \mathrm{com-}$ pared to the second step of decomposition ranging from 330 to $326^{\circ} \mathrm{C}$. At TG endset, all the samples rapidly decomposed with weak heat $\left(\mathrm{J} / \mathrm{mg} \times 10^{-3}\right)$ and a rapid rate of decomposition $(\mathrm{mg} /$ min) over TG onset. This has been revealed through a general increase in the heat $(\mathrm{J} / \mathrm{mg})$ and rates $(\mathrm{mg} / \mathrm{min})$ of decomposition of CECs with increasing peak temperatures corresponding to DTA and DTG, respectively. Prior to TG onset, the weight loss of samples at $100^{\circ} \mathrm{C}$ may be assigned to their respective moisture content $(\%, \mathrm{w} / \mathrm{w})$. Cured epoxy showed moisture content of 1.46. A remarkable reduction in the moisture content to 1.17 was observed for CECs synthesized at a MWCNT concentration of 0.1 , which was subsequently increased to 1.49 at a MWCNT concentration of 0.3 . However, control of such decomposition rates was observed with an increase in the concentration of MWCNTs up to 0.2 (Table 1). On an individual basis, at the TG onset temperature, cured epoxy decomposed at rates of 0.45 at $281^{\circ} \mathrm{C}$ and 0.49 at $330^{\circ} \mathrm{C}$ with an integrated DTA peak at $284^{\circ} \mathrm{C}$ corresponding to a heat of decomposition of 0.425 . At TG endset, cured epoxy rendered relatively fast decomposition at a rate of 0.70 at $486^{\circ} \mathrm{C}$ with a weak heat of decomposition $\left(\mathrm{J} / \mathrm{mg} \times 10^{-3}\right)$ of 1.09 (Fig. 8a). CECs synthesized at a MWCNT concentration of 0.1 decomposed at rates of 0.46 at $287^{\circ} \mathrm{C}$ and 0.41 at $331^{\circ} \mathrm{C}$ with an integrated DTA peak at $287^{\circ} \mathrm{C}$ corresponding to heat of decomposition of 0.56 . At TG endset, CECs showed fast decomposition at a rate of 0.63 at $504^{\circ} \mathrm{C}$ with a weak heat of decomposition of 1.40 at $504^{\circ} \mathrm{C}$ (Fig. 8b). At TG onset, CECs synthesized at a MWCNT concentration of 0.2 decomposed at rates of 0.50 at $265^{\circ} \mathrm{C}$ and 0.39 at $326^{\circ} \mathrm{C}$ with an integrated DTA peak at $287^{\circ} \mathrm{C}$ corresponding to a heat of decomposition of 0.63 . At TG endset, CECs displayed moderate decomposition at a rate of 0.65 at $501{ }^{\circ} \mathrm{C}$ with a weak heat of decomposition of 1.40 at $504^{\circ} \mathrm{C}$ (Fig. 8c). At TG onset, CECs synthesized at a MWCNT concentration of 0.3 decomposed at a single rate of 0.52 at $282^{\circ} \mathrm{C}$ with a monotonous DTA peak corresponding to a heat of decomposition 0.67 at $283^{\circ} \mathrm{C}$ At TG endset, CECs showed rapid decomposition at a rate of 0.80 at $515^{\circ} \mathrm{C}$ with a weak heat of decomposition of 1.80 at $520^{\circ} \mathrm{C}$ (Fig. $8 \mathrm{~d}$ ).

\section{Conclusions}

The authors investigated SCC assisted dispersion of various concentrations (phr) of MWCNTs ranging from 0.1 to 0.3 into epoxy resin $(0.1 \mathrm{~mol})$ at various pressures (psi) ranging from 1200 to 1800 at $90^{\circ} \mathrm{C}$, an $1500 \mathrm{rpm}$ over $1 \mathrm{~h}$. The capability of SCC to enhance the dispersion of MWCNTs into epoxy has been revealed through pressure driven van Hove singularities via UVvisible spectra, microscopy, and DC electrical conductivity. Dispersion of MWCNTs up to a concentration of $0.2 \mathrm{phr}$ has been optimized. Further increase in the concentration of MWCNTs to 0.3 resulted in reaggregation of MWCNTs with size $(\mu \mathrm{m})$ ranging from 1.54 to 3.65 into the epoxy matrix. The CECs processed up to a MWCNT concentration of $0.2 \mathrm{phr}$ at $1800 \mathrm{psi}$ in SCC rendered enhanced mechanical, thermal, an thermomechanical properties, improved DC electrical conductivity, and reduced wear behavior compared to cured epoxy. The increase in the storage modulus and $\mathrm{Tg}$ was indicative of restricted movement of polymer chains, which is ascribed to a strong interaction presented between MWCNTs and epoxy chains, as supported by SEM and AFM analyses. The present study provides an environmentally benign method of dispersing MWCNTs into epoxy assisted with SCC, resulting in CECs with improved dispersion and physical properties.

\section{References}

[1] Li L, Zheng X, Wang J, Sun Q, Xu Q. Solvent-exfoliated and functionalized graphene with assistance of supercritical carbon dioxide. ACS Sustain Chem Eng, 1, 144 (2012). http://dx.doi.org/10.1021/ sc3000724.

[2] Hao J, Lian Y, Guan L, Yue D, Guo X, Zhao S, Zhao Y, Ibrahim K, Wang J, Qian H, Dong J, Yuan H, Xing G, Sun B. Supercritical synthesis and characterization of SWNT-based one dimensional nanomaterials. Nanoscale, 3, 3103 (2011). http://dx.doi. org/10.1039/C1NR10217F

[3] Ye S, Wu F, Ye XR, Lin Y. Supercritical fluid assisted synthesis and processing of carbon nanotubes. J Nanosci Nanotechnol, 9, 2781 (2009). http://dx.doi.org/10.1166/jnn.2009.1325.

[4] Zheng X, Xu Q, Li Z. Supercritical $\mathrm{CO}_{2}$-driven, periodic patterning on one-dimensionals carbon nanomaterials. Sci China Chem, 53, 1525 (2010). http://dx.doi.org/10.1007/s11426-010-3106-0.

[5] Li Z, Andzane J, Erts D, Tobin JM, Wang K, Morris MA, Attard G, Holmes JD. A supercritical-fluid method for growing carbon nanotubes. Adv Mater, 19, 3043 (2007). http://dx.doi.org/10.1002/ adma.200602483.

[6] Li Z, Jaroniec M, Papakonstantinou P, Tobin JM, Vohrer U, Kumar S, Attard G, Holmes JD. Supercritical fluid growth of porous carbon nanocages. Chem Mater, 19, 3349 (2007). http://dx.doi. org/10.1021/cm070767r.

[7] Bertoncini M, Coelho LAF, Maciel IO, Pezzin SH. Purification of single-wall carbon nanotubes by heat treatment and supercritical extraction. Mater Resh, 14, 380 (2011). http://dx.doi.org/10.1590/ S1516-14392011005000051

[8] Wang JS, Wai CM, Shimizu K, Cheng F, Boeckl JJ, Maruyama B, Brown G. Purification of single-walled carbon nanotubes using a supercritical fluid extraction method. J Phys Chem C, 111, 13007 (2007). http://dx.doi.org/10.1021/jp073374o.

[9] Hiramatsu M, Hori M. Preparation of dispersed platinum nanoparticles on a carbon nanostructured surface using supercritical fluid chemical deposition. Materials, 3, 1559 (2010). http://dx.doi. org/10.3390/ma3031559.

[10] Wang J, Khlobystov AN, Wang W, Howdle SM, Poliakoff M. Coating carbon nanotubes with polymer in supercritical carbon dioxide. Chem Commun, 1670 (2006). http://dx.doi.org/10.1039/ B600441E.

[11] Fifield LS, Dalton LR, Addleman RS, Galhotra RA, Engelhard MH, Fryxell GE, Aardahl CL. Noncovalent functionalization of carbon nanotubes with molecular anchors using supercritical fluids. J Phys Chem B, 108, 8737 (2004). http://dx.doi.org/10.1021/ jp0379771. 
[12] Wang XB, Liu ZM, Hu PA, Liu YQ, Han BX, Zhu DB. Nanofluids in carbon nanotubes using supercritical $\mathrm{CO}_{2}$ : a first step towards a nanochemical reaction. Appl Phys A, 80, 637 (2005). http://dx.doi. org/10.1007/s00339-003-2264-8.

[13] Nguyen VH, Shim JJ. Supercritical fluid-assisted synthesis of a carbon nanotubes-grafted biocompatible polymer composite. Compos Interfaces, 20, 155 (2013). http://dx.doi.org/10.1080/1568 5543.2013 .765140 .

[14] Liu Z, Han B. Synthesis of carbon-nanotube composites using supercritical fluids and their potential applications. Adv Mater, 21, 825 (2009). http://dx.doi.org/10.1002/adma.200800609.

[15] Yue B, Wang Y, Huang CY, Pfeffer R, Iqbal Z. Polymeric nanocomposites of functionalized carbon nanotubes synthesized in supercritical $\mathrm{CO}_{2}$. J Nanosci Nanotechnol, 7, 994 (2007). http:// dx.doi.org/10.1166/jnn.2007.220.

[16] Huang YY, Terentjev EM. Dispersion of carbon nanotubes: mixing, sonication, stabilization, and composite properties. Polymers, 4, 275 (2012). http://dx.doi.org/10.3390/polym4010275.

[17] Ma PC, Mo SY, Tang BZ, Kim JK. Dispersion, interfacial interaction and re-agglomeration of functionalized carbon nanotubes in epoxy composites. Carbon, 48, 1824 (2010). http://dx.doi.org/ 10.1016/j.carbon.2010.01.028

[18] Papanicolaou GC, Papaefthymiou KP, Koutsomitopoulou AF, Por$\tan$ DV, Zaoutsos SP. Effect of dispersion of MWCNTs on the static and dynamic mechanical behavior of epoxy matrix nanocomposites. J Mater Sci, 47, 350 (2012). http://dx.doi.org/10.1007/s10853011-5804-1

[19] Gkikas G, Barkoula NM, Paipetis AS. Effect of dispersion conditions on the thermo-mechanical and toughness properties of multi walled carbon nanotubes-reinforced epoxy. Composites B, 43, 2697 (2012). http://dx.doi.org/10.1016/j.compositesb.2012.01.070.

[20] Garg P, Singh B, Kumar G, Gupta T, Pandey I, Seth RK, Tandon RP, Mathur R. Effect of dispersion conditions on the mechanical properties of multi-walled carbon nanotubes based epoxy resin composites. J Polym Res, 18, 1397 (2011). http://dx.doi. org/10.1007/s10965-010-9544-8

[21] Prolongo SG, Burón M, Gude MR, Chaos-Morán R, Campo M, Ureña A. Effects of dispersion techniques of carbon nanofibers on the thermo-physical properties of epoxy nanocomposites. Composites Sci Technol, 68, 2722 (2008). http://dx.doi.org/10.1016/j. compscitech.2008.05.015.

[22] Chen H, Jacobs O, Wu W, Rüdiger G, Schädel B. Effect of dispersion method on tribological properties of carbon nanotube reinforced epoxy resin composites. Polym Test, 26, 351 (2007). http:// dx.doi.org/10.1016/j.polymertesting.2006.11.004.

[23] Song YS, Youn JR. Influence of dispersion states of carbon nanotubes on physical properties of epoxy nanocomposites. Carbon, $\mathbf{4 3}$ 1378 (2005). http://dx.doi.org/10.1016/j.carbon.2005.01.007.

[24] Guo P, Chen X, Gao X, Song H, Shen H. Fabrication and mechanical properties of well-dispersed multiwalled carbon nanotubes/epoxy composites. Composites Sci Technol, 67, 3331 (2007). http:// dx.doi.org/10.1016/j.compscitech.2007.03.026.

[25] Hosur M, Barua R, Zainuddin S, Kumar A, Trovillion J, Jeelani S. Effect of processing techniques on the performance of Epoxy/ MWCNT nanocomposites. J Appl Polym Sci, 127, 4211 (2013). http://dx.doi.org/10.1002/app.37990.

[26] Gupta ML, Sydlik SA, Schnorr JM, Woo DJ, Osswald S, Swager TM, Raghavan D. The effect of mixing methods on the dispersion of carbon nanotubes during the solvent-free processing of multiwalled carbon nanotube/epoxy composites. J Polym Sci B, 51, 410 (2013). http://dx.doi.org/10.1002/polb.23225.

[27] Martone A, Formicola C, Piscitelli F, Lavorgna M, Zarrelli M, Antonucci V, Giordano M. Thermo-mechanical characterization of epoxy nanocomposites with different carbon nanotube distributions obtained by solvent aided and direct mixing. eXPRESS Polym Lett, 6, 520 (2012). http://dx.doi.org/10.3144/expresspolymlett. 2012.56.

[28] Karippal JJ, Murthy HNN, Rai KS, Krishna M, Sreejith M. The processing and characterization of MWCNT/epoxy and CB/epoxy nanocomposites using twin screw extrusion. Polym-Plast Technol Eng, 49, 1207 (2010). http://dx.doi.org/10.1080/03602559.2010.4 96413.

[29] Jin FL, Park SJ. Recent advances in carbon-nanotube-based epoxy composites. Carbon Lett, 14, 1 (2013). http://dx.doi.org/10.5714/ CL.2012.14.1.001.

[30] Frømyr TR, Hansen FK, Olsen T. The optimum dispersion of carbon nanotubes for epoxy nanocomposites: evolution of the particle size distribution by ultrasonic treatment. J Nanotechnol, 2012, 545930 (2012). http://dx.doi.org/10.1155/2012/545930.

[31] Jiménez-Suárez A, Campo M, Gaztelumendi I, Markaide N, Sánchez M, Ureña A. The influence of mechanical dispersion of MWCNT in epoxy matrix by calendering method: batch method versus time controlled. Composites B, 48, 88 (2013). http://dx.doi. org/10.1016/j.compositesb.2012.12.011.

[32] Prolongo SG, Meliton BG, Del Rosario G, Ureña A. Simultaneous dispersion and alignment of carbon nanotubes in epoxy resin through chronoamperometry. Carbon, 50, 5489 (2012). http:// dx.doi.org/10.1016/j.carbon.2012.07.037.

[33] Glaskova T, Zarrelli M, Aniskevich A, Giordano M, Trinkler L, Berzina B. Quantitative optical analysis of filler dispersion degree in MWCNT-epoxy nanocomposite. Composites Sci Technol, 72, 477 (2012). http://dx.doi.org/10.1016/j.compscitech.2011.11.029.

[34] Foltran S, Cloutet E, Cramail H, Tassaing T. In situ FTIR investigation of the solubility and swelling of model epoxides in supercritical $\mathrm{CO}_{2}$. J Supercrit Fluids, 63, 52 (2012). http://dx.doi. org/10.1016/j.supflu.2011.12.015.

[35] Guadagno L, De Vivo B, Di Bartolomeo A, Lamberti P, Sorrentino A, Tucci V, Vertuccio L, Vittoria V. Effect of functionalization on the thermo-mechanical and electrical behavior of multi-wall carbon nanotube/epoxy composites. Carbon, 49, 1919 (2011). http:// dx.doi.org/10.1016/j.carbon.2011.01.017.

[36] Guadagno L, Vertuccio L, Sorrentino A, Raimondo M, Naddeo C, Vittoria V, Iannuzzo G, Calvi E, Russo S. Mechanical and barrier properties of epoxy resin filled with multi-walled carbon nanotubes. Carbon, 47, 2419 (2009). http://dx.doi.org/10.1016/j.carbon.2009.04.035.

[37] Allaoui A, El Bounia N. How carbon nanotubes affect the cure kinetics and glass transition temperature of their epoxy composites? A review. eXPRESS Polym Lett, 3, 588 (2009). http://dx.doi. org/10.3144/expresspolymlett.2009.73. 